\title{
Reply to "Further considerations on 'Towards the origins of over-dispersion in beta source calibration' by Hansen et al., radiation measurements, 2018" by Munish Kumar
}

\author{
Autzen, M.; Hansen, V.; Murray, A.S.
}

Published in:

Radiation Measurements

Link to article, DOI:

10.1016/j.radmeas.2020.106446

Publication date:

2020

Document Version

Peer reviewed version

Link back to DTU Orbit

Citation (APA):

Autzen, M., Hansen, V., \& Murray, A. S. (2020). Reply to "Further considerations on 'Towards the origins of over-dispersion in beta source calibration' by Hansen et al., radiation measurements, 2018" by Munish Kumar. Radiation Measurements, 138, [106446]. https://doi.org/10.1016/..radmeas.2020.106446

\section{General rights}

Copyright and moral rights for the publications made accessible in the public portal are retained by the authors and/or other copyright owners and it is a condition of accessing publications that users recognise and abide by the legal requirements associated with these rights.

- Users may download and print one copy of any publication from the public portal for the purpose of private study or research.

- You may not further distribute the material or use it for any profit-making activity or commercial gain

- You may freely distribute the URL identifying the publication in the public portal 


\title{
Reply to "Further considerations on 'Towards the origins of over- dispersion in beta source calibration' by Hansen et al., Radiation
}

\section{Measurements, 2018" by Munish Kumar}

\author{
M. Autzen ${ }^{1}$, V. Hansen ${ }^{1}$ and A. S. Murray ${ }^{2}$ \\ ${ }^{1}$ Center for Nuclear Technologies, Technical University of Denmark, Frederiksborgvej 399, 4000 Roskilde \\ ${ }^{2}$ Nordic Laboratory for Luminescence Dating, Aarhus University, Ris $\varnothing$ Campus, Frederiksborgvej 399, \\ 4000 Roskilde
}

Providing accurate calibration of the dose rates from beta sources used in laboratory irradiations is important when using luminescence for dose reconstruction. While the dose rate can be increased by increasing the activity of the source, this is associated with an increased radiation exposure risk, and is expensive. Instead, it has been suggested that the dose rate to the target sample can be increased by mounting the sample on a high Z material (Murray, 1981; Ingram et al., 2001; Goedicke, C., 2007; Greilich et al., 2008; Autzen et al., 2017 and Hansen et al., 2018)

Recently, Kumar (2019) commented on this suggestion, particularly citing the work of Hansen et al. (2018). He used the Rad Pro on-line calculator to derive the contribution from bremsstrahlung to the total dose rate when irradiating quartz grains on high Z substrates. From this he argued that, when irradiating on platinum, the bremsstrahlung contribution to the total dose rate is $35 \%$; this could be of concern because of the reported higher luminescence efficiency for low energy photons (Mejdahl, 1970; Attix, 1972; Alvaro et al. 2012; Guérin et al. 2018). We were very surprised by Kumar's estimate of the relative significance of the bremsstrahlung contribution, and have since used Geant4 to model bremsstrahlung production, and its contribution to (a) the total dose rate to quartz and (b) the ionisation rate, when irradiating on various substrates. We found that the photon contribution to dose rate was $<0.1 \%$. This is not surprising, given the backscattered photon and electron spectra published by Autzen et al. (2017) for various $5 \mathrm{~mm}$ thick substrates. 
We then turned to the Rad Pro Calculator (as used by Kumar, 2018) to derive the beta dose rate from a ${ }^{90} \mathrm{Sr} /{ }^{90} \mathrm{Y}$ beta source with an activity of $20 \mathrm{mCi}$ at a distance of $1.5 \mathrm{~cm}$ and found perfect agreement with the $1.47 \mathrm{~Gy} / \mathrm{min}$ given in Kumar's comment.

In order to use the Calculator to derive the bremsstrahlung contribution to this dose rate we had to make one assumption. There is no option for choosing $\mathrm{Pt}(\mathrm{Z}=78)$ or inputting a user-defined shielding material, and so we selected lead $(Z=92)$ as the closest; we assume that Kumar did the same. The online help file for Rad Pro states that the distance to be input when calculating the bremsstrahlung dose rate should be that from source to sample. Using the same source to detector distance as before $(1.5 \mathrm{~cm})$ we find that the contribution of bremsstrahlung to the total dose is approx. $0.04 \%$, three orders of magnitude less than that derived by Kumar, but completely consistent with our GEANT 4 calculations. Kumar also states that he calculated the bremsstrahlung contribution at a sample distance of $0.5 \mathrm{~mm}$ from the substrate. Unfortunately entering this substrate to sample distance is not an option in Rad Pro, but if we instead use $0.5 \mathrm{~mm}$ as the source to sample distance we obtain a contribution from the bremsstrahlung to the total dose rate of $\sim 35 \%$, completely consistent with Kumar's value. The Rad Pro help file is unambiguous concerning the definition of the distance to be entered (source to sample, not shielding to sample), but we presume that Kumar misinterpreted the entry expected in the software, resulting in a significant error in his calculation.

We agree with Kumar that there is significant evidence in the literature (Mejdahl, 1970; Attix, 1972; Alvaro et al. 2012; Guérin et al. 2018) for a difference in luminescence efficiency between low and high energy photons (>120-150 keV). However, both GEANT4 simulations and the Rad Pro Calculator show the bremsstrahlung contribution to the total dose rate to be $<0.1 \%$ when $\mathrm{Pt}$ is used as the substrate. Thus any efficiency difference is extremely unlikely to affect equivalent doses estimated using high $Z$ substrates. We stand by our suggestion in Hansen et al. (2018) of using high-Z substrates to increase the dose rate to (multi-grain) samples, and reaffirm our view that doing so is unlikely to introduce significant additional uncertainty.

\section{Acknowledgements}

M.A receives funding from the European Research Council (ERC) under the European Union's Horizon 2020 research and innovation programme ERC-2014-StG 639904 - RELOS

\section{References}

Alvara, B. de. C. J., Thiago, F. B., Pedro, L. G., Helen, J. K. Manufacturing polycrystalline pellets of natural quartz for applications in thermoluminescence dosimetry, Mater. Res. 2012:15(4):536-543 
Attix, F. H. Topics in Radiation Dosimetry Radiation Dosimetry 1972:1:56-57

Autzen, M., Guerin, G., Murray, A. S., Thomsen, K. J., Buylaert, J. P., Jain, M. The effect of backscattering on the beta dose absorbed by individual quartz grains Radiation Measurements 2017:107:491-497

Goedicke, C. Calibration of ${ }^{90} \mathrm{Sr} /{ }^{90} \mathrm{Y}$-source for luminescence dating using OSL Radiation Measurements 2007:42:1427-1431

Greilich, S., Murray, A. S., Bøtter-Jensen, L. Simulation of electron transport during beta irradiation Radiation Measurements 2008:43:748-751

Guérin, G., Mihailescu, L.-V., Jain, M. Photon energy (8-250 keV) response of optically stimulated luminescence: Implications for luminescence geochronology. Journal of Luminescence 2018:204:135-144

Hansen, V., Murray, A., Thomsen, K., Jain, M., Autzen, M., Buylaert, J.P. Towards the origins of overdispersion in beta source calibration Radiation Measurements 2018:120:157-162

Ingam, S., Stokes, S., Bailey, R. Confirmation of backscattered beta dose enhancement rates based on single aliquot regeneration (SAR) analysis of quartz sand and silt Ancient TL 2001:19(2):51-54

Mejdahl, V. Measurement of environmental radiation at archaeological excavation sites Archaeology 1970:12(2):147-159

Murray, A. S. Environmental Radioactivity Studies Relevant to Thermoluminescence Dating D.Phil. thesis University of Oxford 1980 